\title{
O PEDAGOGO DO TRABALHO: PERFIL PROFISSIONAL E SABERES NECESSÁRIOS PARA A ATUAÇÃO
}

Pedagogue of the work: professional profile and necessary learnings to performance

Raquel Quirino*

João Bosco Laudares**

\section{Resumo}

Este artigo originou-se de nossa pesquisa de Mestrado em Educação Tecnológica no Centro Federal de Educação Tecnológica de Minas Gerais CEFET - MG e discute a educação do trabalhador e a atuação do Pedagogo num espaço pouco usual das reflexões acadêmicas que são as organizações empresariais. Analisamos discursos de pedagogos, atuantes em empresas, sua atuação, seu perfil profissional e a constituição dos saberes que thes dão sustentação para tal. Buscamos compreender o papel deste educador preparado para atuar em escolas e atuante em empresas para contribuir, através das reflexões suscitadas, para a sua formação profissional e a melhoria da educação do trabalhador.

Palavras-chave: Educação do trabalhador. formação profissional do pedagogo. pedagogo do trabalho. Pedagogo nas empresas.

* Professora e Pesquisadora na área de Formação e Qualificação Profissional do Centro Federal de Educação tecnológica de Minas Gerais; mestre em Educação Tecnológica pelo CEFET-MG. Email: quirinoraquel@hotmail.com

** Coordenador e professor do curso de Pós - graduação em Educação Tecnológica do CEFET-MG e professor do curso de Pós - graduação em Ensino de Matemática da PUC-Minas; pesquisador nas áreas de formação e qualificação profissional e de educação matemática; doutor em Educação pela PUC-SP. Email: jblaudares@dppg.cefetmg.br 


\section{Abstract}

This paper is a result of our research in the Master's degree Program in Technology of the Federal Center for Technological Education of Minas Gerais, Brazil (CEFET-MG). It discusses the worker's education and the pedagogue's performance in a not very usual space of the academic reflections that are the managerial organizations. We analyzed speeches of Pedagogues in companies, their performance, their professional profile and the constitution of the knowledge that support them. We looked for to understand the educator's role to act in schools and in companies to contribute, through the raised reflections, to the improvement of their professional education and to the worker's education.

Keywords: Worker's Education. Pedagogues Professional Education. Pedagogue of the Work. Pedagogue in the Companies.

\section{INTRODUÇÃO}

Este artigo originou-se de nossa pesquisa de Mestrado em Educação Tecnológica do CEFET-MG e discute a educação do trabalhador e a atuação do Pedagogo nas organizações empresariais.

Histórica e culturalmente o pedagogo sempre atou na educação escolarizada e sua inserção na educação nas empresas tem se dado de maneira importante, porém lenta e gradual; por isso, pouco se pesquisou sobre esta sua atuação.

Diante da reduzida produção sobre o tema, realizamos uma revisão bibliográfica de autores das áreas de gestão de pessoas, educação, trabalho-educação e pedagogia empresarial, para analisar, inferir e tecer considerações sobre a parte empírica do trabalho.

Com questionários abertos e entrevistas individuais, o trabalho de campo possibilitou-nos ouvir os pedagogos em serviço nas empresas captando, a partir do exercício de sua prática, características próprias do seu perfil profissional, seus espaços de atuação, visão sobre a profissão, opiniões sobre os programas educativos das empresas e assim, evidenciar a contribuição que tem dado à educação do trabalhador. 
A escuta dos sujeitos e a análise dos discursos na pesquisa qualitativa é parte importante dos levantamentos e captamos a percepção de dentro da situação investigada verificando a dimensão epistemológica da sua prática profissional. $\mathrm{O}$ rol de saberes demandados para o seu trabalho nas empresas possibilitou-nos elencar os saberes necessários para a sua formação profissional e para sua atuação nestes espaços.

\section{O CONHECIMENTO: FATOR DE PRODUÇÃO. A EMPRESA: ESPAÇO EDUCATIVO}

A sociedade atual transita da sociedade industrial para a sociedade do conhecimento. Para Drucker (1997), as atividades que ocupam o lugar central das organizações não são mais aquelas que visam produzir ou distribuir objetos, mas as que produzem e distribuem informação e conhecimento.

Nesta sociedade, embora não seja política das empresas, tampouco da sociedade, a democratização e a disseminação generalizada do conhecimento, as formas de organização do trabalho e os modelos de gestão de pessoas, trazem pressupostos de novas formas de valorização do saber do trabalhador e implicam numa necessidade de qualificação e requalificação constantes, mas nem sempre acessíveis a todos.

Os investimentos em capital intelectual e a gestão do conhecimento sintetizam a idéia de que o saber do trabalhador constitui fator de produção estando em evidência no mercado de trabalho no momento atual. Tal constatação tem levado diversas empresas a investirem no desenvolvimento de seus empregados e tem contribuído para a redefinição e a adoção de diferentes padrões de gestão de pessoas. Embora com interesses voltados para a produtividade e o lucro, tais empresas têm se tornado espaços educativos para o trabalhador.

Leite (1994, p. 71) mostra que a fragmentação do trabalho, com o fim do artesanato e o desenvolvimento tecnológico dos sistemas de organização do trabalho taylorista-fordista, traz uma constante desqualificação do trabalhador que tem uma expropriação progressiva e acumulativa do seu saber e de sua autonomia pelo capital. 
Segundo Küenzer $(1999$, p.13), à medida que o saber do trabalhador é incorporado à máquina, cujo manuseio ou acompanhamento não exige habilidades específicas, a relação de trabalho é determinada pela nítida separação entre as atividades intelectuais e instrumentais.

A reestruturação produtiva transforma radicalmente esta situação e com a crescente incorporação de novos princípios científicos e tecnológicos ao processo de trabalho, as habilidades cognitivas, até então restritas a poucos trabalhadores, passam a ser requeridas para todos os demais, independentemente de seu nível hierárquico e função desempenhada.

O desenvolvimento científico-tecnológico e seus efeitos no mundo do trabalho e nas relações sociais implicam uma nova construção cultural e conseqüentes modificações nos processos laborais e educativos.

No atual contexto, as capacidades intelectuais do trabalhador e os seus conhecimentos passam a ter destaque e adquirem valor como um novo e principal fator de produção.

Para Deluiz (2001, p. 7),

(...) O lado luminoso (desse processo) é a possibilidade de um trabalho com novos conteúdos, a partir de novas concepções gerenciais e da introdução de tecnologias que exigem maior base de educação geral, além de novos requisitos e atributos de qualificação profissional.

Porém, Küenzer (1998, p. 38) avalia que

(...) essas novas determinações mudariam radicalmente $o$ eixo da formação de trabalhadores, caso ela fosse assegurada para todos, o que na realidade não ocorre. (...)

Ainda nas idéias de Küenzer, evidenciamos que as exigências do mundo do trabalho na sociedade do conhecimento implicam numa reestruturação do processo educacional, tanto no que se refere ao ensino profissionalizante, quanto às atividades educativas das empresas, de modo a formar trabalhadores de novo tipo, intelectual, técnica, ética e politicamente comprometidos com a construção de uma nova sociedade. 
Nesta sociedade, a ênfase recai sobre o conhecimento, pois este se tornou o recurso essencial da economia. O eixo da riqueza e do desenvolvimento desloca-se de setores industriais tradicionais intensivos em mão-de-obra e capital, para setores cujos produtos, processos e serviços são intensivos em tecnologia e conhecimento.

\section{(...) esta nova sociedade traz como recurso econômico básico ou "meios de produção" não mais o capital, a terra, nem a mão-de-obra. O maior capital da nova sociedade é e será o conhecimento. (Drucker, 1997, p.16)}

Neste contexto, Saviani (1994, p.160) observa que na sociedade capitalista moderna o saber é meio de produção e, como tal, deve pertencer exclusivamente à classe dominante. Porém, na medida em que para produzir, o trabalhador precisa dominar algum tipo de saber, inserese a contradição na essência do capitalismo: $o$ trabalhador não pode ser proprietário dos meios de produção, não pode deter o saber, mas sem 0 saber, ele também não pode produzir.

Muito embora muitas organizações estejam longe de atingir um estágio de desenvolvimento e ainda encontram-se na era industrial, nas organizações denominadas high tech, para assegurar a capacitação do trabalhador e a conseqüente vantagem competitiva, verificamos um maior investimento no capital intelectual, aquilo que corresponde à soma do conhecimento de todos os seus empregados.

Os altos investimentos feitos em equipamentos caros e sofisticados, somados ao baixos níveis de qualificação do trabalhador, à necessidade de melhoria de produtividade e a alta competitividade enfrentada pelo mercado em níveis internacionais, têm levado as empresas a investirem, na formação e qualificação profissionais dos seus empregados.

Apesar de difundir uma concepção de mundo compatível com a racionalidade capitalista, o processo pedagógico desenvolvido pelas empresas desempenha, contraditoriamente, um papel educativo importante, pois através dos cursos e treinamentos oferecidos o trabalhador vai estabelecendo os seus conceitos de saber teórico e prático, o que para Küenzer (1991, p. 64), 
(...) desempenha um papel muito importante no processo de sua constituição para definir seu comportamento político, aceitando em maior ou menor grau a sua condição subalterna, os critérios de valorização do seu trabalho, os critérios de salário e promoções, submetendo-se e/ou discutindo, negociando, reivindicando.

Para que os recursos investidos na educação do trabalhador tragam os retornos desejados pelo capital é necessário que o processo pedagógico seja planejado, implantado e desenvolvido de maneira eficaz, demandando profissionais aptos para sua operacionalização, evidenciando nestes espaços, oportunidades de atuação para o pedagogo do trabalho.

\section{O PEDAGOGO DO TRABALHO: A BUSCA DE UM CONCEITO}

$\mathrm{Na}$ pesquisa teórica encontramos diversas denominações para o Pedagogo atuante fora da escola: "pedagogo empresarial", "educador organizacional", "pedagogo organizacional” e "pedagogo extra-escolar". Na tentativa de compreender as suas similitudes e diferenças, tomamos como referência alguns autores pesquisados.

Segundo Arroyo (1997), etmologicamente, a palavra grega "pedagogo" significa "condutor" - aquele que conduz para o processo educativo - e "pedagogia”, a ciência da educação, sobretudo dos processos de condução de alguém para novos saberes, para o aperfeiçoamento humano.

A partir da concepção de Arroyo, Figueiredo (s.d.), afirma que o pedagogo que realiza atividades voltadas para a orientação profissional, embora não previsto em nenhuma lei, parecer ou resolução relativos à educação no Brasil, constitui-se no pedagogo do trabalho.

Para o autor, o pedagogo do trabalho aparece como mensageiro de uma nova direção para a pedagogia que não tem raízes na nossa história. A ele cabe a função específica de orientação vocacional e profissional do educando, mas enfrenta a difícil tarefa de divulgar valores novos na nossa cultura, os quais ele próprio ainda recusa, vítima que naturalmente é do processo de endoculturação que rejeita esses valores. 
Ao pedagogo do trabalho,

(...) compete apresentar o mundo do trabalho humano: analisar as tarefas sociais, buscar o seu sentido, descobrir interesses que reforçam ou enfraquecem uma aptidão, refletir sobre os preconceitos que dividiram o trabalho humano em dois campos opostos - $o$ aviltante e o nobre. (Figueiredo, s.d.)

Figueiredo (s.d.) considera a escola elitista, responsável pela separação da formação propedêutica da formação profissional e a sociedade capitalista que divide $o$ trabalho em intelectual e manual, os responsáveis pelos desvios da função do pedagogo do trabalho para "pedagogo do ajustamento"; o primeiro incumbido da iniciação do jovem no mundo do trabalho e orientação do trabalhador para 0 aprendizado e desenvolvimento profissional, e o segundo para o ajustamento do homem ao trabalho e aos interesses do capital.

Diversas denominações vêm sendo utilizadas para o pedagogo do trabalho, sendo "pedagogo empresarial", a mais usual e com maior apelo comercial, atraindo inúmeros alunos para os diversos cursos de especialização lato sensu existentes na área, em todo o país ${ }^{1}$.

Boldrin (2000) denomina pedagogo empresarial àquele que se ocupa dos processos de ensino-aprendizagem no âmbito das organizações de qualquer segmento ou dimensão, no setor público ou privado, cuidando do caráter educativo das ações ligadas ao desenvolvimento do trabalhador nas empresas.

Para Bomfin (mimeo), o educador organizacional abarca um conjunto variado de profissões e profissionais que têm como propósito a ação pedagógica de facilitar o processo de ensino aprendizagem nas organizações. E o pedagogo organizacional,

(...) embora mantenha alinhamento com o propósito da ação pedagógica que é o de facilitar o processo de ensino aprendizagem nas organizações, tem um propósito maior e, ao mesmo tempo específico, que é o de se constituir como um especialista, no sentido de formação profissional.

O pedagogo extra-escolar, para Vieira (2001), é aquele que desenvolve atividades educativas fora dos limites da escola e seu campo de 
trabalho integra diferentes tipos de organizações e áreas de atuação através de processos de aprendizagem voltados para o desenvolvimento social interrelacionando a área de educação com diferentes campos temáticos: saúde, esporte e lazer, cultura, profissionalização, meio ambiente, direitos humanos e outros.

Nos conceitos propostos pelos autores, observamos que, o pedagogo atuante nas organizações, embora com denominações diferentes, desenvolve atividades de orientação, condução e operacionalização da educação do trabalhador nas empresas. O que nos possibilita inferir sobre a existência de diferenças entre as denominações é a ideologia embutida na prática destes profissionais e ao significado que vem sendo dado ao seu trabalho nas organizações.

Adotamos “pedagogo do trabalho", preconizada por Figueiredo (s.d.), por entendermos ser este um conceito de profissão que se sustenta numa formação acadêmica específica e, embora tenha o propósito de promover o desenvolvimento humano nas organizações, assim como os diversos profissionais atuantes nesta área, tem um propósito maior e específico, que é o de se constituir como um orientador e condutor da educação do trabalhador. A substituição do termo "pedagogo empresarial" - mais popular e conhecido, por "pedagogo do trabalho" nos possibilita dar um sentido mais amplo de sua atuação do que aquele direcionado, exclusivamente, a empresas privadas de produção de bens, matérias-primas ou serviços.

\section{O PEDAGOGO DO TRABALHO: ONDE ATUA? O QUE PENSA DA PROFISSÃO?}

Por ser crescente a presença de pedagogos em empresas, consideramos relevante evidenciar e estudar a sua prática profissional nestes espaços e, por ser esta atuação um tema ainda pouco estudado e explorado, a pesquisa de campo é um instrumento de fundamental importância para buscar respostas para nossas questões.

Com o objetivo de selecionar os sujeitos que integrariam o corpus da pesquisa identificamos 70 pedagogos em diversas empresas na região de Belo Horizonte e encaminhamos, via internet, um "questionário preliminar". Dos questionários enviados, 22 foram respondidos, correspondendo a 
$31,42 \%$ da população. Utilizando a pesquisa qualitativa, os dados obtidos possibilitou-nos classificar os pedagogos pela sua formação acadêmica, tempo na função, áreas de atuação, atividades desenvolvidas, sua relação com a educação do trabalhador e dificuldades encontradas na profissão,.

Pelo tipo de organização, 83\% estão em empresas prestadoras de serviços: $37,5 \%$ em empresas públicas e 45,5\% em empresas privadas. Os demais $17 \%$ atuam em empresas privadas de produção. Quanto ao tempo de formação, três são formados há mais de 20 anos, cinco há mais de quinze anos e os demais graduados nos últimos 10 anos.

Quanto à educação continuada, 64\% têm curso de pós-graduação lato sensu em pedagogia empresarial, gestão de recursos humanos e outros; dois têm mestrado em educação e um está em fase de doutoramento em administração. No histórico profissional, cinco têm experiência na educação escolar. Os demais iniciaram a carreira na área de RH em empresas. Considerando os anos de atuação na área organizacional a média é de cinco a 20 anos de experiência profissional.

Os espaços de atuação são nas áreas de formação profissional, sendo as mais predominantes a área de recursos humanos: treinamento e desenvolvimento, universidades corporativas, centro de competências, programas de formação profissional, especialização de mão-de-obra e área de consultorias internas e externas: elaboração de projetos educacionais; cursos in company; orientação para o desenvolvimento gerencial; educação continuada.

Quanto aos cargos ocupados: diretor; gerente de recursos humanos; chefe de serviço de ensino; analista de recursos humanos; supervisor pedagógico; pedagogo; orientador profissional.

As principais atividades desenvolvidas são voltadas para a educação formal, em parceria com instituições de ensino e para a educação nãoformal. Nas consultorias o trabalho é direcionado para o desenvolvimento de projetos educativos diversos e para a oferta de cursos profissionalizantes. Pela natureza das organizações nas quais trabalham, atendem também às demandas das comunidades externas com programas de formação e qualificação profissional. Incluem-se também em suas diversas funções: programas de desenvolvimento de lideranças; treinamentos internos e 
externos; elaboração de materiais didáticos; orientação didático-pedagógica de instrutores; condução de treinamentos em sala de aula; realização de diagnósticos; levantamento de necessidades de educação continuada e de treinamento; pesquisa e desenvolvimento de novos serviços; desenvolvimento de textos educativos; reuniões pedagógicas e o gerenciamento de toda a área de RH.

Quanto às dificuldades enfrentadas para o exercício da função, evidenciamos:

dificuldades diversas para sensibilizar a direção da empresa para a importância da educação do trabalhador e mostrar a competência que o pedagogo tem para coordenar as atividades de assessoria educacional fora da escola. Por ser visto, muitas vezes, de forma distorcida no mercado, o pedagogo tem uma atuação limitada. Não há uma imagem nossa como um profissional educador mais abrangente. Pensam que a gente é, apenas professor do ensino fundamental. (PE 04)

Percebemos ser a discriminação e o preconceito, quanto à sua formação acadêmica, uma das grandes dificuldades do pedagogo em sua atuação nas empresas. No seu artigo: "O trabalho como princípio educativo frente às novas tecnologias”, Saviani (1994), possibilita-nos inferir que este comportamento discriminatório é uma questão histórica e cultural. O critério que se padronizou para a educação é a formação escolar. Sempre vista negativamente: "educação não escolar, educação não formal e informal”, para muitos, a educação nas empresas não necessita de acompanhamento de profissionais com conhecimentos específicos para tal e, assim, ainda não conseguem conceber a atuação do pedagogo em outros ambientes a não ser na escola.

Para outros entrevistados há resistência das faculdades de educação pela inserção do pedagogo nas empresas e a formação inadequada nos cursos de pedagogia:

Tive dificuldade de assimilar a educação dentro das empresas. Lá na Faculdade, no curso de Pedagogia nem se podia cogitar a possibilidade de se trabalhar em empresas, 
éramos discriminados na hora. Não nos preparam para estes espaços e ficamos totalmente perdidos sem conseguir fazer a transposição do que é ensinado no curso para o nosso trabalho real. (PE 11)

\section{A contribuição para a educação do trabalhador}

Apesar das dificuldades apontadas, os pedagogos sentem-se realizados na profissão, entendem os princípios de sua formação profissional, vêem com muito otimismo a sua atuação nas organizações e defendem o seu trabalho como de fundamental importância para que os projetos organizacionais se transformem em educação de fato:

Temos uma formação mais humanista do que outros profissionais que atuam nesta área, o que nos possibilita entender o processo educativo sob o ponto de vista filosófico, social, ético e dos valores morais. Muitas empresas estão investindo na educação dos seus empregados $e$ não há ninguém na área empresarial que conheça sobre educação como nós. A nossa grande chance de contribuir está no planejamento, quando distribuímos os conteúdos, planejamos os tempos, as metodologias e avaliação. Aí podemos ir além do que a empresa precisa e oferecer mais ao trabalhador. (PE 05)

O pedagogo também pode atuar como orientador dos trabalhadores e gerentes. Isto traz desafios, mas possibilidades de contribuição para a melhoria da educação nas empresas:

Quando os empregados me procuram para saber se devem fazer os cursos que a empresa convocou, eu sempre digo que eles devem estudar, fazer todos os cursos, participar de todos os programas pensando no futuro como profissionais e não apenas no que a empresa quer e precisa. Acredito que a maior contribuição que podemos dar ao trabalhador é ajudá-lo a construir uma visão de mundo mais abrangente e levá-los a compreender que custa muito caro investir em 
educação e que o conhecimento é o seu maior patrimônio. (PE 04)

Alguns dos entrevistados enfatizaram a angústia e o medo de não poder fazer mais pela educação do trabalhador, devido à força do sistema e a resistência das gerências:

Temos de olhar os interesses da empresa mas também buscar os interesses do trabalhador. Isto não é fácil e nem sempre possível. Precisamos de coragem para encarar a situação e estar preparados para entrar em conflito. Quando não conseguimos sensibilizar os gestores, temos algumas vezes de fazer opções dolorosas para não perdermos o emprego. (PE 06)

Em síntese, a visão holística advinda da sua formação ampla nas ciências aplicadas à educação, o pensamento estruturado, o desenvolvimento cognitivo e o modelamento mental que o curso de Pedagogia proporciona, aliados à organização e planejamento, dão ao pedagogo condições de desenvolver um trabalho multidisciplinar nas organizações empresariais, trazendo inúmeras contribuições para toda a sociedade.

\section{OS SABERES DO PEDAGOGO DO TRABALHO}

Conforme Tardif (2000),

damos aqui à noção de "saber" um sentido amplo, que engloba os conhecimentos, as competências, as habilidade (ou aptidões) e as atitudes, isto é, aquilo que muitas vezes foi chamado de saber, saber-fazer e saber ser. (Tardif, 2000:10-11)

Mostraremos adiante que este sentido amplo reflete a opinião dos próprios pedagogos entrevistados a respeito de seus saberes, o que deu ao nosso estudo a possibilidade de verificar a dimensão epistemológica de sua prática profissional.

Assim,

chamamos de epistemologia da prática profissional o estudo do 
conjunto dos saberes utilizados realmente pelos profissionais em seu espaço de trabalho cotidiano para desempenhar todas as suas tarefas. (Tardif, 2002:255.)

Durante as entrevistas os pedagogos fizeram referências aos seus saberes de maneira casual e espontânea, mas quando questionados diretamente, percebemos uma certa dificuldade na elaboração das respostas, demonstrando que nem sempre é fácil teorizar a sua prática e formalizar seus saberes.

Chegamos a uma categorização dos saberes - aqueles que entendemos, todo pedagogo do trabalho deve dominar, dividindo-os em dois grandes grupos:

- saberes profissionais

- saberes experienciais

Apoiamo-nos nas categorias propostas por Saviani (1996), em seu ensaio: "Os saberes implicados na formação do educador", no qual o autor aponta um conjunto de saberes que, em princípio, todo educador deve dominar e, por isso, integram o processo de sua formação. Para análise das categorias de saberes não preconizadas por Saviani (1996), utilizamos os trabalhos de Tardif (2002) e as reflexões de Freire (1996), sobre os "saberes necessários à prática educativa”, aqueles “(...) saberes demandados pela prática educativa em si mesma, qualquer que seja a opção política do educador ou educadora." (Freire, 1996, p. 23)

Embora tais autores abordem saberes para o trabalho pedagógico escolar e para a formação docente, entendemos ser de grande valia a discussão desses estudos com os relatos apresentados pelos pedagogos do Trabalho entrevistados, uma vez que todos tiveram esta formação acadêmica no curso de Pedagogia

Para facilitar a análise e a compreensão dos saberes citados tratamos os saberes profissionais e os saberes experienciais em categorias distintas.

\section{Saberes profissionais}

Ainda em Tardif (2002, p. 36), os saberes profissionais são o conjunto de saberes transmitidos pelas instituições de formação, o conhecimento 
socialmente produzido e que integram os currículos dos cursos. Nessa perspectiva, esses conhecimentos se transformam em saberes destinados à formação científica ou erudita dos pedagogos.

Nesta categoria, na qual prevalecem os processos sistemáticos de aquisição dos saberes, utilizamos as propostas de Saviani (1996): saberes pedagógicos; saberes didáticos-curriculares e saberes específicos.

Para nossos entrevistados, este saber é chamado de saber acadêmico e é adquirido através da formação inicial ou contínua, em cursos de graduação e pós-graduação, onde entram em contato com as ciências da educação.

Porém, Tardif (2002), revela que trinta anos de pesquisa mostram uma relação de distância entre os saberes profissionais e os conhecimentos universitários.

Essa distância pode assumir diversas formas, podendo ir da ruptura à rejeição da formação teórica pelos profissionais, ou então assumir formas mais atenuadas como, adaptações, transformações, seleção de certos conhecimentos universitários a fim de incorporá-los à prática. Desse ponto de vista, a prática profissional nunca é um espaço de aplicação dos conhecimentos universitários. Ela é, na melhor das hipóteses, um processo de filtração que os dilui e os transforma em função das exigências do trabalho; ela é, na pior das hipóteses, um muro contra o qual vêm se jogar e morrer conhecimentos universitários considerados inúteis, sem relação com a realidade do trabalho diário nem com os contextos concretos de exercício da função. (...). (Tardif, 2002, p. 257)

Em seus relatos, os pedagogos, corroboram Tardif (2002) e alegam ser a formação acadêmica excessivamente teórica, ideológica e academicista. Paradoxalmente, reconhecem a importância dos conhecimentos adquiridos durante o curso para a sua prática profissional, em especial aqueles advindos das ciências aplicadas e dos fundamentos da educação:

A formação ampla nas ciências, que obtemos no curso de Pedagogia, nenhum outro curso oferece e isto é um grande 
diferencial para nós. Há hoje uma grande tendência das empresas voltarem o olhar para a humanização e aí, entender de Psicologia, Sociologia, Antropologia e sobretudo Filosofia é necessário para qualquer profissional que trabalha com gestão de pessoas. (PE 07)

A estes saberes "produzidos pelas ciências da educação e sintetizados nas teorias educacionais (...)” (Saviani, 1996, p. 149) denominamos saberes pedagógicos.

Para os autores, os saberes pedagógicos articulam-se com as ciências da educação sendo difícil distingui-los e traduzem também as doutrinas pedagógicas dominantes, incorporando-as à formação profissional dos educadores, fornecendo um arcabouço ideológico à profissão e algumas formas de saber-fazer.

Para os entrevistados, os conteúdos de cunho técnico-instrumental estudados nas diversas disciplinas do curso de pedagogia contribuíram muito para a sua atividade profissional atual:

No meu trabalho tenho que supervisionar o instrutores, revisar planos, metodologias e avaliaçôes, apresentar relatórios das atividades para a gerência e isto não conseguiria sem ter feito as disciplinas de didática, supervisão pedagógica, as metodologias de ensino, avaliação e sem preencher tantos relatórios de estágio. (PE 03)

Em Saviani (1996), encontramos o saber didático-curricular, como aqueles saberes técnicos relativos às formas de organização e realização da atividade educativa e, em sentido mais específico, o domínio do saber-fazer que implica não apenas os procedimentos técnico metodológicos, mas a dinâmica do trabalho pedagógico.

Outra categoria apresentada por Saviani (1996) e aplicada em nossa análise, são os saberes específicos, aqueles que o profissional deve dominar e é de fundamental importância para sua atuação. Uma abordagem diferente sobre os saberes específicos necessários ao educador e considerada mais adequada para a análise dos saberes do pedagogo do trabalho, é a proposta de Falcão Filho (2000): a necessidade do educador conhecer o ambiente externo 
e interno da organização onde trabalha, as suas estruturas formal e informal, a cultura e o clima organizacionais, bem como as variáveis que os determinam.

É necessário ter uma visão abrangente sobre o funcionamento das empresas e conhecimentos sobre gestão, comunicação oral e escrita, além dos meios tecnológicos para outras formas de educação à distância, internet, intranet, ead. É preciso também conhecer sobre gestão organizacional, gestão de pessoas, técnicas de treinamento, recrutamento e seleção, psicologia organizacional, teorias da administração e outras Só com os conhecimentos relativos ao funcionamento escolar fica muito difícil trabalhar em empresas. (PE 05)

\section{Saberes experienciais}

Pelas categorias de Saviani (1996) e Tardif (2002), trataremos os saberes experienciais como: saber comportamental-atitudinal e saber críticocontextual.

Em Saviani (1996, p.151), os saberes da experiência não podem ser considerados como "um tipo de saber ao lado dos demais", isto porque não se trata de um conteúdo diferenciado, mas de uma forma que pode estar referida indistintamente aos diferentes tipos de saber.

Porém, Tardif (2002), considera que os educadores na prática de suas funções e de sua profissão desenvolvem alguns saberes específicos, baseados em seu trabalho cotidiano e no conhecimento de seu meio e que devem ser investigados. Esses saberes, segundo o autor, brotam da experiência e são por ela validados.

Eles incorporam-se à experiência individual e coletiva sob a forma de habitus e de habilidades, de saber-fazer e de saberser. Podemos chamá-los de saberes experienciais ou práticos. (Tardif, 2002:39)

A partir das certezas e dos condicionantes da experiência prática os pedagogos julgam sua formação acadêmica. Segundo eles, muita coisa se aprende com a prática, pela experiência, tateando e descobrindo, no próprio trabalho: 
A educação nas empresas traz uma diversidade de situações que você vive e que vai te ajudando a construir os saberes que você precisa. No mundo empresarial as coisas acontecem mais rápido, de maneira mais dinâmica, as situações são sempre novas e diferentes e você é sempre cobrado para fazer o melhor em menos tempo. Não há escola melhor pra se aprender a trabalhar. (PE 09)

Esses e outros comportamentos e atitudes revelados pelos pedagogos em seus discursos, denominamos saberes comportamentaisatitudinais. Esta categoria compreende o domínio dos comportamentos e vivências necessários ao trabalho educativo nas organizações.

Abrange atitudes e posturas inerentes ao papel atribuído ao educador, tais como disciplina, pontualidade, coerência, clareza, justiça e eqüidade, diálogo, respeito às pessoas dos educandos, atenção às suas dificuldades etc. Trata-se de competências que se prendem à identidade e conforma a personalidade do educador. (Saviani, 1996, p.148)

Os entrevistados enfatizam a necessidade de transformar cada experiência vivida em oportunidade de aprendizado e reconhecem a importância da criatividade e da curiosidade como partes integrantes do repertório de saberes do pedagogo, o que Freire (1996, p. 35) chama de "curiosidade epistemológica":

A curiosidade como inquietação indagadora, como inclinação ao desvelamento de algo, como pergunta verbalizada ou não, como procura de esclarecimento, como sinal de atenção que sugere alerta (...).

$\mathrm{O}$ aprendizado oriundo das experiências e do contato com os colegas de trabalho, aliados à criatividade e à curiosidade, possibilitou aos entrevistados fazer a transposição dos saberes pedagógicos e didáticocurriculares dos meios acadêmicos para a prática educativa nas empresas, sendo também de fundamental importância para a construção dos saberes específicos necessários ao exercício de suas atividades: 
Tive que observar tudo e perguntar muito. Cada oportunidade: reuniões, trabalhos em grupo, visita a fornecedores, eventos, me ensinou muito. Mesmo não estando diretamente ligado ao seu trabalho é preciso que você conheça tudo o que se relaciona com a empresa. (PE 03)

Também a capacidade de comunicar-se e utilizar as novas tecnologias foram saberes considerados de grande importância:

$E$ fundamental que você domine os conceitos de "fim e meio". A educação é o fator fim e a comunicação é o meio. Se você já possui os conhecimentos necessários sobre a educação, também tem que saber se expressar, convencer, persuadir buscando atingir o seu objetivo maior. Você tem que incorporar o vocabulário e o uso das tecnologias de comunicação da sua nova área de trabalho. (PE 05)

Em seus “saberes necessários à prática educativa”, Freire (1996) nos auxilia na compreensão dos entrevistados quando aborda os valores e princípios; competência profissional e generosidade e, sobretudo, reflexão crítica que o educador deve ter sobre sua prática.

Este saber crítico trata-se de um saber relativo à compreensão das condições sócio-históricas da tarefa educativa. Segundo Saviani (1996) o educador deve compreender o movimento da sociedade identificando suas características básicas e as tendências de sua transformação, de modo a detectar as necessidades presentes e futuras a serem atendidas pelo processo educativo sob sua responsabilidade. É necessário, então, a compreensão do contexto com base no qual e para o qual se desenvolve o trabalho educativo, traduzida aqui na categoria do saber críticocontextual.

Por exercer funções educativas num ambiente em que as ideologias e os valores vigentes são diferenciados dos vivenciados pela escola, a compreensão do contexto no qual e para o qual se desenvolve o trabalho educativo é imprescindível para o pedagogo do trabalho. Os entrevistados reconhecem a dimensão humana do seu trabalho e a importância de uma postura ética voltada para os interesses dos educandos: 
Não é porque a empresa quer que o trabalho seja feito que você vai esquecer que é um educador. É preciso saber negociar, mas sem abrir mão dos seus valores. Os interesses da empresa devem ser atendidos mas você não pode deixar de favorecer o empregado na construção do seu conhecimento, de sua cidadania. Acredito muito numa relação de reciprocidade. É difícil conjugar os interesses das empresas com os interesses dos trabalhadores e nós, pedagogos, podemos contribuir. Não podemos nos deixar corromper pela lógica capitalista e esquecer o que a educação se propõe. (PE 09)

Quando questionados se o seu trabalho poderia ser realizado por outro profissional, nossos entrevistados revelaram a clareza da visão acerca das especificidades do campo profissional e do objeto de estudo/trabalho do pedagogo:

O pedagogo é a pessoa mais indicada para conduzir processos educativos em qualquer lugar. A visão holística e humanizada que o pedagogo tem sobre o seu educando nenhum outro profissional tem, assim como a linguagem, o interesse pela pesquisa, a visão processual e a competência teórica e técnica específica de sua área de atuação. Todos os demais profissionais que atuam na educação nas empresas trabalham em função da manutenção do status quo, nós é que temos de trabalhar em favor da mudança, da transformação. Não podemos nos esquecer que somos educadores, em qualquer lugar que estejamos. (PE 09)

Diante dos aspectos destacados e enfatizados percebemos que um maior domínio e apropriação dos saberes da formação do pedagogo apresentase como norteador das atividades educativas por eles desenvolvidas, assim como a transformação, a mobilização, a reelaboração e a construção de novos saberes em sua prática, são de fundamental importância para a atuação bem sucedida nas empresas. 


\section{CONCLUSÃO}

Como o conhecimento vem se tornando um fator de produção altamente valorizado pelas empresas e o desenvolvimento científico-tecnológico nem sempre é acompanhado pela escolas, torna-se necessário as organizações tomarem sob sua responsabilidade parte da educação do trabalhador.

A demanda das empresas tem levado os seus programas educativos a serem implementados de maneira mais abrangente, superando os tradicionais programas de "treinamento-adestramento" dos modelos tayloristafordista. Neste contexto, para que os recursos investidos na educação do trabalhador tragam os retornos desejados pelo capital é necessário que seja planejada, implantada e desenvolvida de maneira eficaz, demandando, assim, profissionais aptos para sua operacionalização, evidenciando oportunidades de atuação para o pedagogo.

Pesquisas anteriores mostram oportunidades e desafios enfrentados por este profissional nas organizações não escolares (Bomfin, mimeo), os espaços e as principais atividades realizadas por ele (Vieira, 2001) e a reflexão sobre a sua formação acadêmica (Souza, 1988 e Boldrin, 2000).

O nosso trabalho se propôs a contribuir com o desvelamento de questões sobre a pedagogia do trabalho, entendida aqui como a área da Pedagogia que se ocupa da educação do trabalhador nos ambientes organizacionais.

A crescente presença do pedagogo nas organizações empresariais confirma a possibilidade de sua atuação em novas áreas de trabalho e nos dá a oportunidade de inferir que em diversas empresas a formação profissional está sendo tratada de uma maneira mais educativa.

Os pedagogos, sujeitos da pesquisa, levam-nos a conhecer o perfil deste profissional, preparado a priori para atuar em escolas - mas atuante também em empresas, e a contribuição que dá a formação do trabalhador em um ambiente com objetivos e interesses tão diferentes, e até divergentes, da educação escolarizada.

Os entrevistados admitem que os grandes desafios apresentados pela necessidade de transposição dos saberes de um domínio para outro fazem o pedagogo do trabalho refletir sobre sua formação e postura profissionais construindo a sua identidade, a qual, embora diferente, não é divergente, da identidade do pedagogo escolar. $\mathrm{O}$ diferencial entre o pedagogo do trabalho 
e o pedagogo escolar está menos nos saberes mobilizados e utilizados por ambos do que na amplitude de visão em relação ao papel do educador, na concepção da educação e na importância dada ao processo educativo em outros ambientes fora dos "muros" da escola.

Por ser uma área emergente e de grande importância no campo educacional esperamos que os resultados apresentados contribuam para o enriquecimento dos conhecimentos sobre o tema e que sejam pontos de partida para novas pesquisas, pois, muito ainda há de se buscar sobre a educação do trabalhador nas empresas e sobre a pedagogia do trabalho, principalmente neste momento em que tantas mudanças estão ocorrendo no mundo do trabalho e diversas propostas sobre a formação do educador estão sendo discutidas no meio acadêmico.

\section{REFERÊNCIAS}

ARROYO, M. Pedagogia das relações de trabalho. Trabalho e Educação. Belo Horizonte:NETE-UFMG. n.2, ago/dez. 1997.

BOLDRIN, L. C. F. Pedagogia empresarial: que conhecimento e espaço são estes? Uberlândia:UFU.2000. Dissertação de Mestrado.

BOMFIN, D. F. Pedagogia \& pedagogo organizacional: seu universo, desafios e oportunidades de trabalho.(mimeo).

DELUIZ, N. Formação do trabalhador em contexto de mudança tecnológica. Boletim Técnico do SENAC, n.20. jan./abr.1994.

DRUCKER, P. F. Sociedade pós-capitalista. São Paulo:Pioneira,1997.

FALCÃO FILHO, J. L. M. Escola: ambientes, estruturas, variáveis e competências. Ensaio:avaliação e políticas públicas em educação. Belo Horizonte. Vol.8.jul./ set.2000.

FIGUEIREDO, J. C. Quem é o pedagogo brasileiro? Amae Educando. Coletânea n. ${ }^{\circ}$ 1.Belo Horizonte.(Periódico sem data).

FREIRE, P. Pedagogia da autonomia: saberes necessários à prática educativa. São Paulo:Paz e Terra, 1996. 
o pedagogo do trabalho...

KÜENZER, A. Z. A pedagogia da fábrica: as relações de produção e a educação do trabalhador. São Paulo:Cortez,1985.

Reduc, 1991.

. Educação e trabalho no Brasil: o estado da questão.Brasilia:

. As mudanças no mundo do trabalho e a educação: novos desafios para a gestão. IX ENDIPE. Águas de Lindóia, 4 a 8 de mai./1998.

. Educação profissional: categorias para uma nova pedagogia do trabalho. Boletim Técnico do SENAC. Volume 2. n. 25. mar./ago.1999.

LEITE, E. M. O resgate da qualificação. São Paulo: USP. 1994. Tese de doutoramento.

QUIRINO, Raquel. Saberes do Pedagogo para a prática educativa na organizações empresariais. Belo Horizonte: CEFET-MG, 2005 - Dissertação de Mestrado

SAVIANI, D. O trabalho como princípio educativo frente às novas tecnologias. In: FERRETI et al. Novas tecnologias, trabalho e educação. Petrópolis: Vozes, 1994.

. Os saberes implicados na formação do educador. IV Congresso

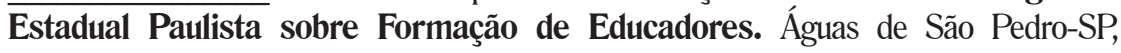
mai./1996.

SOUZA, D. G. Treinamento e desenvolvimento de recursos humanos em empresas: uma opção para o Pedagogo. Niterói: UFF. 1988. Dissertação de Mestrado.

TARDIF, M. Saberes profissionais dos professores e conhecimentos universitários: elementos para uma epistemologia da prática profissional dos professores e suas consequiências em relação à formação para o magistério. Revista Brasileira de Educação, n. 13. jan / fev / mar / abr 2000.

TARDIF, M. Saberes docentes \& formação profissional. Petrópolis: Vozes, 2002.

VIEIRA, M. L. Relatório final do projeto integrado: Análise da relação teoria/prática no processo de formação/atuação de diferentes profissionais da educação. Belo Horizonte: UNI-BH, 2001. 